\title{
Decades of Innovation in Aircraft Design Education
}

\author{
Russell M. Cummings ${ }^{1}$ \\ California Polytechnic State University, San Luis Obispo, CA, 93407 \\ David W. Hall ${ }^{2}$ \\ DHC Engineering, Morro Bay, CA, 93442 \\ Doral R. Sandlin ${ }^{3}$ \\ California Polytechnic State University, San Luis Obispo, CA, 93407
}

\begin{abstract}
Aircraft design has formed the foundation of the aeronautical engineering curriculum at Cal Poly since the inception of the department in 1927. While the focus and approach for teaching aircraft design has changed a great deal over the decades, the importance of the Cal Poly "learn by doing" philosophy has been a constant element. The end result of this decades-long history of innovation and improvement has been the continued success of Cal Poly students in the AIAA design competitions, especially the Undergraduate Team Aircraft Design competition. Details about how the design curriculum has evolved and grown will be discussed, including how non-technical issues have been integrated into the coursework. The details provided should supply insight to students and professional engineers about the aircraft design educational approach at Cal Poly, and hopefully lead to improved design education at other universities.
\end{abstract}

\section{Introduction}

$\mathrm{T}$ HE Aerospace Engineering Department at Cal Poly (formerly named the Aeronautical Engineering Department) has a long history of offering a strong, vibrant aircraft design curriculum for students. ${ }^{1-3}$ The design curriculum, while being quite successful today, was very different in the past and has evolved a great deal over the past sixty years. During the 1930s and 1940s, for example, students learned how to construct and maintain an airplane, but did not learn very much about the theoretical basis for design. Today, students perform the detailed preliminary design of an aircraft, including many of its systems, at a level similar to what industry might expect. This evolution has been greatly enhanced by Cal Poly's past participation in the NASA University Space Research Association (USRA) Program and the NASA Aircraft Multidisciplinary Design and Analysis Fellowship (AMDAF) Program. Also of great importance in promoting design concepts in the curriculum has been the program requirements of the Accreditation Board for Engineering and Technology (ABET) and the American Institute of Aeronautics and Astronautics (AIAA) student design competitions. These programs and organizations have enabled and aided Cal Poly in giving students a more intensive aircraft design experience by allowing them to work on real-world design problems in an educational setting.

While the outsides influences described above were essential to the evolution of the design curriculum, the faculty of the department have also been a key element. Most faculty in the department had real-world experience in various aspects of the aerospace industry, which added some practical knowledge about how engineering and design were performed in industry. These industry-experienced faculty were crucial to the creation of an aircraft design curriculum that is a well-integrated, intensive sequence, requiring integrated knowledge in aerodynamics, flight performance, aircraft structures, propulsion

${ }^{1}$ Professor Emeritus, Aerospace Engineering Department, also Professor of Aeronautics, USAF Academy, AIAA Associate Fellow.

${ }^{2}$ Consultant, also Lecturer (retired), Aerospace Engineering Department, California Polytechnic State University, AIAA Lifetime Senior Member.

${ }^{3}$ Professor Emeritus, Aerospace Engineering Department.

American Institute of Aeronautics and Astronautics 092407 
systems, and stability \& control. The curriculum includes introductory information on aircraft sizing, aircraft operations, weight estimation, performance requirements, maneuvering, propulsion systems, environmental systems, and configuration layout. Issues that are also addressed in the curriculum include environmental impact, economics, airline requirements, and government regulations. Many of the aircraft design problems used in the curriculum have been industry-generated, with industry engineers actively involved in the instructional program via an advisory board. These engineers supply the support, both financial and technical, which helps to make the design curriculum successful.

The design work has been conducted in an interdisciplinary fashion, with design groups working in teams for most of the time. To add more real-world flavor, the senior-level course culminates in a design review attended by working and retired engineers and managers with expertise in aeronautics, manufacturing, propulsion, maintenance, structures, and control systems who come from Boeing, Lockheed Martin, Northrop Grumman, Rolls Royce, General Electric, United Airlines, as well as NASA, the US Air Force, and other government agencies. Students gain valuable insight into the difficulties of designing an aircraft within the constraints of a group project with a deadline. Unfortunately, when we first started asking students to work in this interdisciplinary, team environment, we found that they were not prepared to work well together, since the senior design course was their first in-depth team engineering experience. In addition, student design skills were often inadequate, which should not be surprising, since they had little or no opportunity to practice the art of design in their previous coursework.

We were faced with a dilemma. How could students be given the necessary background in design within the limitations of the curriculum? At the same time we were seeing the need to increase student design skills, pressures external to the university were demanding improved graduation rates and increased student throughput. Most universities across the country were also seeking ways to reduce the total number of units required for graduation, and our engineering curriculum was already at the maximum number of units allowed. Therefore, the overriding constraint on any new approach to design education was that new material could not add units to the existing curriculum. In addition, the curriculum changes had to provide an integrated approach to design from the freshman year through the senior year, with modules taking place throughout the student's academic career. We believed that these restraints were necessary and inviolable.

In order to solve these problems, we first looked at what was being done at other universities. A variety of approaches to give students a unique design experience had been attempted, including teaming freshman with senior design students, ${ }^{4}$ introducing students to engineering concepts in a unified set of courses in the sophomore year, ${ }^{5}$ and teaching aircraft design with international, multidisciplinary teams. ${ }^{6}$ While we admired these approaches, we felt that we needed to develop a curriculum that best tied in with the Cal Poly "learn by doing" educational philosophy (see Ref. 3 for details). There were many dead ends and false starts along the way, but the resulting curriculum proved effective in creating engineers who understood the complexities of the aircraft design process. A summary of the thought processes and efforts in creating the curriculum are reviewed in Ref. 7, and a description of the sophomore aircraft design course that was developed may be found in Ref. 8. Other important aspects of the curriculum have been discussed in detail in Refs. 9-12. Our goal here is to provide a streamlined, end-product view of the design curriculum, so that the reader can avoid some of our mistakes and take advantage of some of our "happy accidents". ${ }^{12}$

\section{Aircraft Design Curriculum Background}

Before discussing the details of how the aircraft design curriculum has evolved over the years, it might be helpful to understand what the curriculum was like in the 1960s and 1970s. The current design sequence was started by Cliff Price, and he was the first person to start collecting design-related materials for the design lab. At that time students took a two-quarter senior-year sequence in aircraft design, which was only marginally integrated into the overall aeronautical engineering curriculum. Each student performed an individual design of an airplane following the design process outlined in an aircraft design textbook, and a different aircraft was designed each quarter by each student.

In the first quarter students were given the task of designing a commercial airliner, with each student designing for a slightly different set of parameters (such as incrementally different takeoff or landing field lengths). This allowed the students to learn the design process on an aircraft that was substantially similar to the other students in the class, but still be responsible for understanding the entire design process on their own. While students did learn the basic design concepts (including the cyclical nature of design), the true 
integration of aircraft systems was only minimally covered, especially since each student was designing their own aircraft, leaving little or no time for design details. Also, students had little or no experience in working together as a team on a design, something which we learned later was important, but not necessarily easy to accomplish. This led us to a long, sometimes painful, path of innovation.

The second quarter involved designing an airplane of the student's choosing (with the approval of the instructor). This allowed the students some creativity in choosing a category of aircraft and application that they wanted to pursue, but also left the student alone to develop requirements and usability for the aircraft. While these programmatic issues are important in aircraft design, they may not be well suited for undergraduates to develop without a better background in the overall design process. Once the students chose the aircraft category and requirements, the same design process used on the first airplane was followed on the second airplane. The work of both quarters resulted in a design analysis report and a welldrafted three-view drawing, which formed the basis for the grading in the course.

\section{Major Innovation Initiatives}

While the aircraft design course described in the preceding section was productive and served an educational purpose, there were many short-comings to the individual nature of the approach. The faculty at the time, especially Doral Sandlin, were constantly thinking of ways to improve the design curriculum, but often only within the constraints of individual sections of the course. Al Andreoli experimented with using design teams in the late 1980s, having all of the students in a section functioning as a single team trying to solve a transportation problem. Teams of twenty students or more often would not function well, and led to a great deal of problems in coordination and evaluation for the faculty.

In an effort to aid in the incorporation of a team-centered design approach to the curriculum in the late 1980s, Doral Sandlin proposed that Cal Poly participate in the NASA USRA Advanced Design Program (ADP). The program was established in 1984 in an attempt to address concerns about the lack of design education in aerospace programs at U.S. universities, and was expanded to include aeronautics programs in 1986. ${ }^{13,14}$ The USRA ADP had the following objectives (among others): ${ }^{13}$

- "to provide motivation and resources for students in engineering "capstone" design courses and to provide meaningful contact with NASA engineering personnel

- to introduce real (and potential) NASA projects into university engineering programs, allowing students and faculty the opportunity to work on "real-world" projects

- to provide motivation for United States students to obtain graduate degrees

- to strengthen ties between the NASA centers and university engineering departments

- to encourage industry participation through lectures at schools, sponsorship of class research projects, and placement of students as interns at research and development labs where they work on space and aeronautics design projects related to their university design curricula

- to develop a core group of universities, highly qualified in advanced engineering design, with the potential to serve as a resource to NASA's formation and implementation of future mission concepts

- to aid in developing university engineering design curricula through involvement in NASA research projects and to improve the overall United States educational capability in space and aeronautics engineering design"

- "to enhance the design experience for students in our universities, with the goal of graduating better design engineers and enhancing our competitive position in the world marketplace

- to replenish the nation's pool of aerospace designers."

The Cal Poly participation in ADP included teaming with aircraft designers from NASA Ames Research Center and working on the design of supersonic transport aircraft. Whether anything will come from the designs that resulted is unsure, but the benefits of participation in the program were tremendous. From our perspective, the USRA ADP program was extremely successful in achieving their objectives, and the impact of the program on our curriculum can still be seen today. Specifically, ADP allowed for improved education through the use of teaching assistants to work with the design students, greatly improving the contact hours the students received while working on their designs. Also, ADP provided a forum for the students to present their work to NASA engineers and faculty of other engineering schools, 
something which obviously improved the excitement (and tension) of the students. To put it mildly, the USRA ADP objectives listed above make for a good description of many of the features of the design program at Cal Poly. As shown in Fig. 1, the USRA involvement started a flurry of activity at Cal Poly leading to significant changes in the design curriculum and our related association with industry and government agencies. The outcome of our participation with USRA was a change in the senior design course to a three quarter sequence, where the first quarter was dedicated to teaching the design process, design space, and initial sizing, while the second and third quarters were devoted to design, usually beyond just the conceptual phase. The design curriculum of the early 2000s was largely modeled on this approach, and will be discussed in the next section.

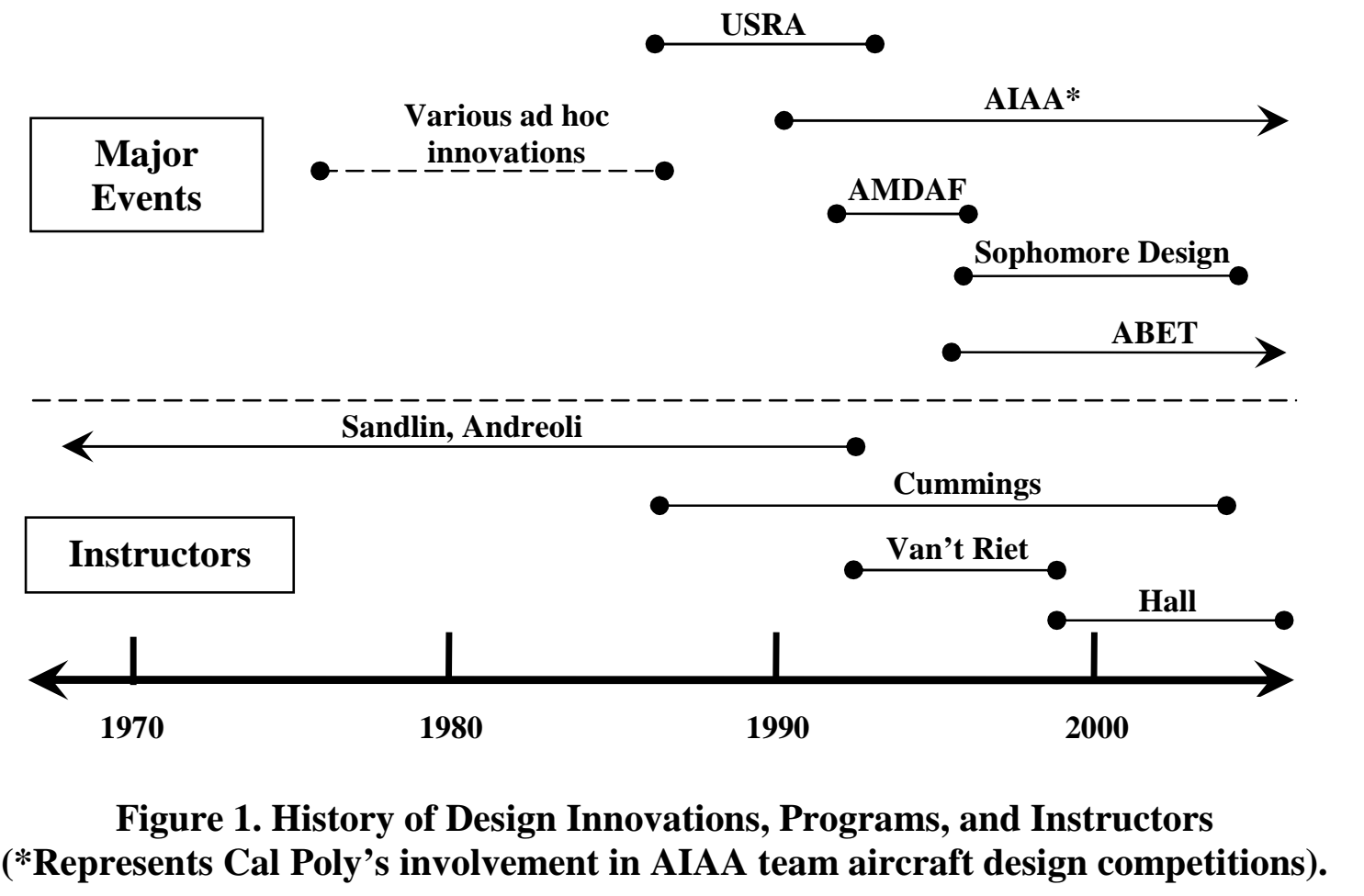

The next major impact on the aircraft design curriculum took place in the first half of the 1990s when Cal Poly was awarded a major research grant from NASA from the Aeronautics Multidisciplinary Design and Analysis Fellowship (AMDAF) program. Through the AMDAF program, NASA granted five universities major funding to improve aircraft design research and education by developing modern tools to aid in the design process. The universities participating in AMDAF included Virginia Tech, Georgia Tech, Clemson, BYU, and Cal Poly; Cal Poly was the only primarily undergraduate university selected to participate. Multidisciplinary design and analysis (MDA) has become the normal mode of operation within most aerospace engineering companies over the past few decades, but universities had not changed their education of engineering students to follow this trend in industry. With the support of Boeing, McDonnell Douglas, and Northrop Grumman, a multidisciplinary team of faculty, students, and industry partners evaluated the aeronautical engineering curriculum at Cal Poly. The goal was to introduce MDA themes without adding courses or units to the existing curriculum. Both analytic and educational tools for MDA were developed and implemented. Major changes to the undergraduate curriculum were also implemented, including: an improved integration of design within engineering science courses, creation of more design content in non-design courses, creation of a graduate design course, and the integration of multidisciplinary approaches, especially manufacturing, business, human factors, and team dynamics into the aircraft design course. ${ }^{7}$

The innovations offered through the AMDAF program were quickly followed by significant changes to the Accreditation Board for Engineering and Technology (ABET) criteria in the mid to late 1990s. Specifically, Robert R. Furgason wrote a letter to engineering deans making some observations that we have found to be very true: 
One continual comment, especially from employers, is that our engineering graduates are well prepared in the quantitative aspects of the scientific, mathematical and engineering components of their education, but they often lack what we might term the 'soft' or 'people' skills; that is, the ability to communicate effectively - write, speak, and listen; the ability to work effectively in teams; an appreciation of the economic, environmental, safety, and social factors present in most settings that often dictate the approach that is used; and a realization of the political environment in which they workboth internal and external In education, we stress the 'right answer' approach and our graduates do not have a good appreciation that most things we deal with are ambiguous and we seek best answers involving many subjective elements. Our curricula should be modified to incorporate these aspects into the educational process. ${ }^{15}$

These observations led ABET to require engineering programs to integrate design throughout their curriculums, and not just complete a student's engineering education with a capstone design experience. This notion integrated well with the changes and innovations we had made as a result of USRA and AMDAF, and was a natural extension of the work that we were already doing. The desire to infuse design throughout the curriculum, coupled with our experiences from AMDAF, led to the creation of a sophomore design course, and the integration of seniors and sophomores (loosely) in the design process, something which we found incredibly motivational for the younger students.

The final motivation for the now decade long series of innovations to the curriculum was our decision to begin participating in the AIAA Team Aircraft Design Competitions, as well as various other AIAA student design competitions. This participation had begun in the early 1990s, but the innovations being made in the curriculum, coupled with the addition of Robert van't Riet (formerly of McDonnell Douglas) to the faculty in the mid 1990s, led to a rapid growth of our participation in the AIAA competitions. More will be discussed about these competitions later, but for now it is important to note that the competitions served to give our students a goal to strive for as they worked their way through our newly changed design curriculum. It is probably safe to say that USRA, AMDAF, and ABET provided the motivation for the faculty to improve the curriculum, but AIAA provided the motivation for our students to fully take advantage of those improvements.

\section{Curriculum Innovations}

The primary motivation in the changes we made to the design curriculum was the inability of our students to fully grasp the multidisciplinary nature of design. The various skills that are required to be a good designer, as described in the preceding section, could not be crammed into the existing course. In addition, we wanted the curriculum changes to provide an integrated approach to design from the freshman year through the senior year, with modules taking place throughout the student's academic career. We believed that these restraints were inviolable. A summary of the thought processes and efforts in creating the curriculum are reviewed in Ref. 7.

Perhaps the most important early curricular change to take place was a direct outgrowth of the USRA experience. The aircraft design faculty realized that the two quarter senior design sequence was inadequate for giving students an in-depth exposure to aircraft design. Doral Sandlin led the change to a year-long aircraft design sequence, with the first quarter being used to teach basic design concepts (such as aircraft performance, the design approach, and cost analysis), and the following two quarters serving as the primary design courses, with a single design being pursued by teams of students, rather than the earlier course which concentrated on individual aircraft designs. ${ }^{1}$

The year-long sequence led to experimenting with various lecture/laboratory formats for the design course, such as all lecture mode the first quarter followed by all laboratory mode in the final two quarters, as well as other variations on the lecture/laboratory combination. While we found that every combination we tried had its positive and negative aspects, there was no "perfect" combination of lecture and lab, except for the observation that the farther we went through the year, the less time we needed to spend in lecturing students, and the more time we needed to give to them to work on their designs.

A major impact of the AMDAF program and ABET on the design curriculum was a concentrated effort to integrate design throughout the curriculum. This was done via adding design elements to existing engineering science courses (such as aerodynamics and flight mechanics), as well as changing other course 
completely, or even adding new courses if required. The faculty of the department included a team-teaching approach to segments of the curriculum where these issues were relevant, with the goal of integrating the multidisciplinary design approach throughout the curriculum, from freshman engineering courses through master's-level design courses. This included a new freshman engineering design course, a new CAD/CAM modeling course, a new sophomore design course, and a comprehensive approach to design in the senior design sequence. This formed the basis for the creation of the sophomore design course in the late 1990s (see Fig. 1).

Given our desire to introduce students to design at the sophomore level, we faced the same dilemma that others had found ... the students do not "know" enough to perform the design of an aircraft. ${ }^{16,17}$ Therefore, the first need in the course was to teach them engineering concepts "just in time" and "just enough", supplementing such teaching with computer tools that allow analysis to be performed at levels beyond the scope of the student's abilities. The second, less tangible, but equally important, need of the sophomore design course was for the faculty to mentor the students in design philosophy and engineering practice. ${ }^{9} \mathrm{We}$ have found that sophomores can learn a great deal from designing a complex system, in spite of their lack of background knowledge. When technical knowledge is missing, software or semi-empirical design methods are offered to the students. In addition, a large amount of design information is supplied to the students in the classroom and via a course web page. We have used new, innovative aircraft requirements to get the students to think about requirements, markets, and the importance of customer-based thinking in the design cycle.

We outlined six primary goals of the sophomore design course (not listed in order of importance): ${ }^{8}$

- introduce students to aeronautical engineering fundamentals

- introduce teamwork basics

- introduce students to market/ethical/social considerations in design

- introduce conceptual design philosophy

- introduce presentation skills, and

- immerse and mentor students in the design process.

The course ended in a "mini symposium", where engineers from industry and government labs volunteered to critique the sophomore designs. The students performed dry runs of their final presentations prior to the mini-symposium and iterated on presentation materials and techniques. Each team turned in a comprehensive final report that described their technical work, their teamwork, and allowed them to reflect on the overall design and team processes. The report and presentation were required to address the following areas:

- purpose of the airplane

- description of the market-who will buy the plane?

- comparison of the airplane with at least two other competing airplanes (if they exist)

- 3-view drawing of the airplane

- estimates of the following: weight, payload, cost, airfoil selection, wing planform, wing aerodynamics, flaps, control surfaces, basic configuration and layout of the airplane, including the landing gear, cruise conditions, engine performance estimates, and performance analysis at the cruise altitude.

While any one of the curriculum innovations mentioned above could not, by itself, lead to the growth and success of our design students over the years, all of the innovations coupled together obviously played a major impact on the course and student learning.

\section{Pedagogical Innovations}

While the curriculum changes discussed above were essential to our success in teaching students aircraft design, they only form part of the overall picture. We do not believe that curriculum changes alone were responsible for the improvements to our program. Perhaps just as important have been the numerous pedagogical changes that have been made to the course sequence over the decades, primarily as the result of the various instructors and teaching assistants who have taught the course. While it would be difficult to 
know which innovations were made by which person, we will attempt to give an overview of the totality of innovations which have been made, from the seemingly minor to the major. While we will concentrate on the primary innovations that were made, they come in no particular order of importance: we believe that all of these innovations were essential.

\section{A. Working Field Trips and Contact with Industry}

In the early 1990s the aircraft design students started taking field trips to various aircraft manufacturing sites, such as Boeing in Seattle or McDonnell Douglas in Long Beach. The initial trips were primarily just field trips to see manufacturing facilities and meet alumni of the department. However, the field trips have greatly evolved over the life of the senior aircraft design experience at Cal Poly. By the year 2000, a consistent set of visits each year capitalized on the strengths and interests of each participating organization, although the philosophical makeup of the trips was the same for each. Participating companies included the Boeing Phantom Works in Huntington Beach, Lockheed Martin Skunk Works in Palmdale, Northrop Grumman Integrated Systems in El Segundo and, later, the U.S. Air Force Flight Test Center at Edwards Air Force Base. The trips consisted of plant tours and sales pitches by human resources personnel on the benefits of working for the sponsoring organization. More importantly, we started to use the trips as a chance for the students to make detailed briefings on their design work. Real world System Requirements Review (SRR), Preliminary Design Review (PDR), and Critical Design Review (CDR) took place on the various trips, which were organized to coincide with the educational requirements of the course.

As a result, design seniors spent at least a week preparing and practicing briefings for whichever company they visited with the intention of presenting detailed descriptions of their technical work and their separate and collective rationales for important design decisions. This also led to a host of skill development that was never truly planned: the absorption of industrial etiquette. Students learned important lessons, including: do not put your shoes on the chair in the Executive Conferences Room, do not eat all the Danish before your host arrives, shorts and a tee-shirt might not be the best dress for Boeing, make notes of the questions that are being asked, and send a thank you letter to your host.

It was not lost on the seniors, many of whom were going to graduate and start their careers soon, that these trips were an excellent way to showcase their talents to prospective employers, and this became a strong motivating factor for doing well in senior design. The briefings brought a real-world flavor to the students, and had a large impact on some of their non-engineering skills, including a focus on presentation quality and developing delivery skills as part of an engineer's skill set. The contacts made by the students during the trips also gave them some experienced engineering contacts for discussing concepts and asking questions as the designs evolved throughout the year, which greatly added to the mentoring aspects of the course, which will be discussed later (see Refs. 10 and 12 for more details).

However, these industry and government contacts had even more benefits beyond the direct impact on the student's designs. As an example, the V/STOL project office at NASA Ames Research Center offered to fund summertime research into subjects of joint interest if students would be actively involved both on campus and at Ames. We set up a series of cooperative agreements between Cal Poly and NASA that were the major funding vehicles for summertime work during most of the first half of the current decade. The engineers at Ames were concerned that their ability to do in-house conceptual aircraft design had eroded with several years of severe cutbacks in the aeronautics budget, and they turned to Cal Poly to provide that capability. Both the Boeing Phantom Works in Huntington Beach and the Rolls-Royce Liberty Works in Indianapolis joined these cooperative agreements. As a result, Cal Poly aeronautical engineering students got to work with industry and government staff on a wide variety of aeronautical projects that, in several instances, resulted in job offers when they graduated. NASA got high quality, quick turnaround conceptual design work of immediate applicability to the needs of the V/STOL project office and coined the term "SWAT (Students With ATtitude) to describe the summer teams of faculty and students assembled to respond to their design needs. Students quickly adopted the name and were proud to be members of the "Cal Poly SWAT Team". 


\section{B. Teamwork}

One of the first changes made to the aircraft design course during the late 1980s was to place the students in teams in order to perform their design work. This was deemed necessary because of the growing scope of the designs, and because it was obvious that our students would be functioning in team environments when they entered industry. One of the unforeseen results of this change, however, was that we found the students were not well prepared to work in teams, nor did they often have the people skills required to make their teams successful.

The primary obstacle at most universities seems to be the typical engineering educational style, which promotes independence over teamwork. Students are put through several years of engineering science courses as individuals, where group work is discouraged and even penalized. The problem with this approach has been noted by engineering educators at many universities, and has led to various curriculum modifications (see Refs. 4-6). We believe that for the senior design experience to be truly valuable from a team viewpoint, the students must be given team skills earlier in the curriculum (and throughout the curriculum). It is for this reason, along with our observations of students in our design courses and the input we received from industry, that we believe team building to be a crucial area for the success of multidisciplinary design.

Team skills of students were observed as part of the AMDAF program, and tutorials and team-building exercises were developed to help the students. ${ }^{18}$ These tools were also introduced to students in the lower division courses so that their team skills would be well developed by the time they reached the senior design class. Both the sophomore design introduction as it was taught in the early 2000's and the senior aircraft sequence strongly emphasized the importance of teamwork, and focused early lab exercises on team building.

\section{Design Symposium}

As early as 1990 the aircraft design class began holding a Design Symposium at the end of the year. Engineers from industry and government labs were invited to attend, with a typical audience consisting of between 15 and 30 technical experts. As time went on, the invitation included a design newsletter that described the student teams and their design goals; this newsletter proved to be very productive in keeping industry members interested in Cal Poly and the student's work. An additional newsletter was also sent out in late summer to inform the attendees of the results of the AIAA competitions, since most of the student teams would submit their designs to AIAA after the symposium, including the suggestions and feedback from the industry engineers.

The symposiums consisted of in-depth presentations by each design team, including high quality handouts from each team. The handouts included pictures and contact information for each student, as well as an overview of the design. This gave the reviewers a way to connect the students with the presentation being given. The student teams were subjected to industry-level questioning, with various members of each team serving as the "experts" on the various aspects of each design. Besides providing the students with valuable feedback about their designs, the symposium also added some real-world pressure and a deadline for completing design work. Since the symposium was held about two weeks prior to the AIAA deadline for submitting design reports, the students had enough time to make last minute improvements or corrections to their work prior to submission. These design symposiums (and the preceding meetings with the industry engineers during the plant tours) have provided a great catalyst to the work of the students and have proven to be invaluable in our student's success.

\section{A Good Lab Space and Well-Stocked Reference Library}

From 1963 to 2007, the aircraft design laboratory was located in a forty foot square room with no interior partitioning on the third floor of Engineering West, which was originally designed to be an architectural studio with a great deal of ambient light and cross-ventilation. In the laboratory was an extensive library of aviation and aeronautics related books, periodicals, reports, and copies of designrelated papers, none of which was thoroughly catalogued despite repeated attempts over the years to do so. A surprising amount of material had been donated by alumni. 
The lab was funded in early years by the Aeronautical Engineering Department and, from the mid1990s on, by donations from industry. This increased the design instructor's workload to include soliciting annual donations from major aerospace industry and government sponsors, but paid off with a degree of flexibility not typical of most academic funding environments in terms of providing first-rate equipment such as computers, design-related software, printers, plotters, and projectors, as well as copies of design textbooks or specialty area texts as references. In addition to the copies of design texts in the lab library itself, each sophomore and senior design team had reference drawers assigned to them with additional copies of pertinent texts. Contents of the drawers were tailored to provide references particular to the pertinent design subject. This added funding provided for teaching/lab assistants for both the sophomore design course and the senior aircraft design course, as well as supplies such as paper, printer cartridges, and even paid for field trips most years.

Beginning in academic year 1999-2000, the design instructors had "office space" in one corner of the design lab to add an industry feeling to work being performed in the design courses, with the "boss" located in one part of a large, contiguous work area. This also meant that students had instant access to the design instructor for questions or feedback. The work area itself was arranged to facilitate teamwork, and students were encouraged to sit with their assigned teams during lecture periods as well as lab work periods.

\section{E. Preparation and Organization for the Student Teams}

To further drive home the importance of performing well in team environments, the design instructor, teaching assistants, and sometimes visiting design alumni held weekly technical interchange meetings (TIMs) similar to status meetings held in industry, with students expected to informally present their recent work and to receive critiques. There were also weekly meetings with the team leads and the design instructor and teaching assistants which were focused on management challenges that the leads experienced so that each lead could see that other leads experienced similar problems and all could work together to assure the lab ran as smoothly and productively as possible. Team leads were expected to set their own work deadlines within the overall structure of the year-long sequence and its external milestones and deliverables. Again, the emphasis was on milestones, beginning with periodic briefings to industry and preparation of draft technical reports, which eventually evolved into draft proposals, and then into the finished products to be sent to AIAA. The AIAA competitions set external deadlines, as did the annual design symposium, which was usually held the third week in May and coupled with one meeting of the Aerospace Engineering Department's Industrial Advisory Board. This gave student teams anchors to design their work flow around.

Most fall quarter work was individual in nature in years when the Request for Proposal (RFP) subject permitted it, and began with descriptions of the overall design process and how it would be tailored to an academic environment over the coming year. Students then began reading the RFP, and re-reading it and discussing it, and providing rapid turnaround investigations of specific areas that might be design drivers or show stoppers. As the academic year progressed and students developed a more detailed knowledge of the particular design subject, they were encouraged to re-read the RFP and develop a compliance matrix as their proposals took shape to assure they addressed RFP requirements and desirements.

Among the non-technical opportunities offered early most fall quarters was a creativity class taught by a retired industry configurator and frequently attended by members of industry and NASA. Other nontechnical aspects of fall quarters included detailed discussions of the role of differing management styles and personality types in team work. This frequently led students to appreciate the role of engineering managers in getting high quality, highly technical work done to external deadlines.

The combination of periodic field trips with design reviews presented at aerospace companies rather than at school, as well as draft proposal submittal deadlines, provided opportunities for senior aircraft design students to see and appreciate the value of periodic reviews of their work and critiques aimed at providing a responsive and high quality final product. This allowed the students the time to, "let the wine age and mature before the company is asked to drink it."

\section{F. There is no Substitute for Putting a Plaque on the Wall!}

In the early 2000's, the faculty redecorated the Aeronautical Engineering Department office and took down a series of AIAA plaques commemorating wins in past competitions, some dating back to as early as 
1990-1991. The design instructor and teaching assistants moved the plaques into the aircraft design lab and had them mounted over the thirty foot long whiteboard at the front of the room so they would be constantly visible to students and visitors to the lab. The power of this "wall of fame" (as the students called it) was truly amazing in terms of wordlessly driving home the success of past year design teams and setting a bar for current and future years. During the early 2000's the department held an open house for prospective students and alumni, and the aircraft design lab was an annual part of the department tour. Senior design students said that one aspect of their decision to attend Cal Poly in aerospace engineering was the winning tradition exemplified by the plaques. Part of every fall quarter in aircraft design was a bid/no-bid decision by the students and design faculty including teaching assistants. Every year, students elected to participate in the AIAA competition, saying later that they wanted to see their own plaque on the wall and that became a major motivator during the design year.

\section{G. Final Observation: Pay Attention to Serendipity and Synchronicity}

Moving the design instructor's "office" to one corner of the aircraft design lab turned out to have both a positive and a negative effect on students. For the most part, students saw the instructor's presence as a beneficial thing-they could ask questions and chat about design-related work or engineering careers anytime the instructor was present without having to wait for posted office hours. This encouraged students to interact with design faculty much as they would with a lead engineer or manager at an aerospace company. The other reason for moving the design instructor's office into the lab was that there was an almost palpable energy in the lab that waxed and waned with the workload in senior aircraft design and in other courses. Being aware of, and being part of, that cyclic energy energized the instructors and teaching assistants.

On the other hand, some years students thought the instructor was spying on them and judging their coursework surreptitiously. This came to a head in early 2002 when the aircraft design seniors asked the instructor to limit his time in the lab to days and an hour or so after class ended-in any case, to be out of the lab by about $7: 30 \mathrm{pm}$. People familiar with psychological concepts will suspect projection as the motivator and this was partly true; the other reason was to get the instructor out of the lab early enough that senior design students could use the projection equipment to watch DVD movies as they worked into the wee hours. As the design faculty monitored student activity during these periods, frequently with the covert assistance of the janitor who was a valuable member of the design staff, it became apparent that students were watching movies to take breaks from their design work or catch-up work for other courses and using the movie evenings for informal team building and not using the unsupervised evenings strictly for socializing.

During spring quarter 2000 the second author assisted the first author with his introductory sophomore aerodynamics/design course which was taught in another lab across the street from the aircraft design lab. This course had been offered in two sections fall quarters and one section spring quarters for years. Descriptions of its inception and evolution are presented in Ref. 8. With the two of us involved in the course, the focus rapidly evolved from mostly aerodynamics to mostly design, with the lecture material pertaining predominantly to classical aerodynamics and performance. As this sophomore design course continued to evolve, the design portion of it became much like fall quarter of the senior aircraft design sequence. Students made "field trips" across the street from one lab to the other to use references and invariably engaged in conversations with their peers in the other lab. The seniors made sarcastic references to the "ankle biters" invading their senior design lab, but unanimously enjoyed tutoring them and helping them find pertinent references in the senior design lab library. The result was unprecedented interaction that benefited both groups. Sophomores heard what the next two years of their Cal Poly experience would be like and seniors were consistently surprised by how much they had learned in their aeronautical engineering courses that they could pass on to the sophomores. After two or three years of these interactions, they became something both groups looked forward to and even expected. Rites of passage figure into this as well. Several sophomore students, at the conclusion of their design course, said that they did not really consider themselves Cal Poly aeronautical engineering students until they had pulled an end-of-quarter "all nighter" in the aircraft design lab.

In summary, one can focus on the major issues like the quality and quantity of lecture material and the lecture/laboratory hour split, but the experience of the design instructors related here has been that the "minor" factors described above determined the quality of the overall experience each Cal Poly students 
received, and set the tone in their early careers for their experiences in industry. Judging by feedback from many project engineers and engineering managers in industry, the Cal Poly hands-on approach to aircraft design produced junior engineers who could hit the ground running, were able to grasp the interrelated aspects of designing and producing aircraft, and who could acquit themselves well in technical briefings of their work.

\section{Examples of Student Designs}

Cal Poly's integrated approach to teaching aircraft design is illustrated by the following four examples. Most of the students in these senior aircraft design teams had benefited from an introductory sophomore design class and from the presence every summer of student teams working with faculty, industry, and NASA on STOL airliner studies for future generations of civilian regional airliners. A brief description and drawing of each configuration is included. All of these designs won the AIAA Undergraduate Team Aircraft Design Competition.

\section{A. Whirlwind in 1999}

The faculty advisor for this design was Robert van't Riet, and the design was for a short takeoff and landing carrier onboard delivery aircraft (STOL COD) which had to carry aircraft engines, passengers, and typical at-sea priority replenishment cargo. Performance requirements were such that turboprops could be used for propulsion and overall size was similar to the Grumman C-2 Greyhound predominantly because of physical space limitations on the carriers. The STOL requirement coupled with a free deck landing and takeoff requirement drove most of the designs to tilt wing solutions. Team Whirlwind, however, selected an autogyro solution to shorten takeoff and landing distances considerably. To assure the success of the design students created CFD models of the flowfield effects through the rotor. This is an excellent example of thinking outside the box by a group of students.

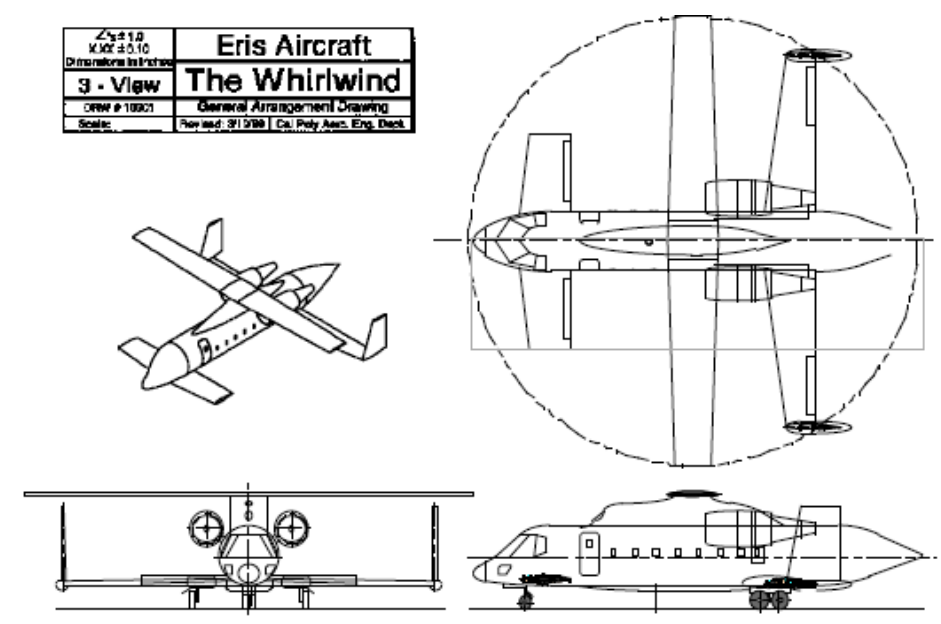

Figure 2. The Whirldwind, AIAA 1998-1999 Competition Winner.

\section{B. Cyclops in 2000}

The following year was the first one design under the mentorship of the second author, and the RFP addressed a subsonic cruise missile carrier with a $5000 \mathrm{~nm}$ outbound range and a $1000 \mathrm{~nm}$ return range capable of carrying ten cruise missiles. The RFP asked students to consider alternate uses for the aircraft and this turned out to be a red herring that forced all of the responding teams with the exception of Cyclops to design a manned aircraft with cargo hauling capability. Team Cyclops looked at that, but adopted an unmanned aerial vehicle (UAV) approach where the carrier aircraft was essentially a reusable first stage for the missiles. The operational concept (CONOPS) Team Cyclops proposed was that the aircraft would be stored until needed, then loaded and flown. "Aircrews" would be trained on UAV ground station simulators which they had also used as ground stations for operational missions. There were no ancillary 
missions the aircraft could fulfill, hence, Cyclops weighed in at slightly over half the takeoff gross weight (TOGW) of its competition and significantly lower operating and life cycle costs. This also represents a great example of thinking outside the box.

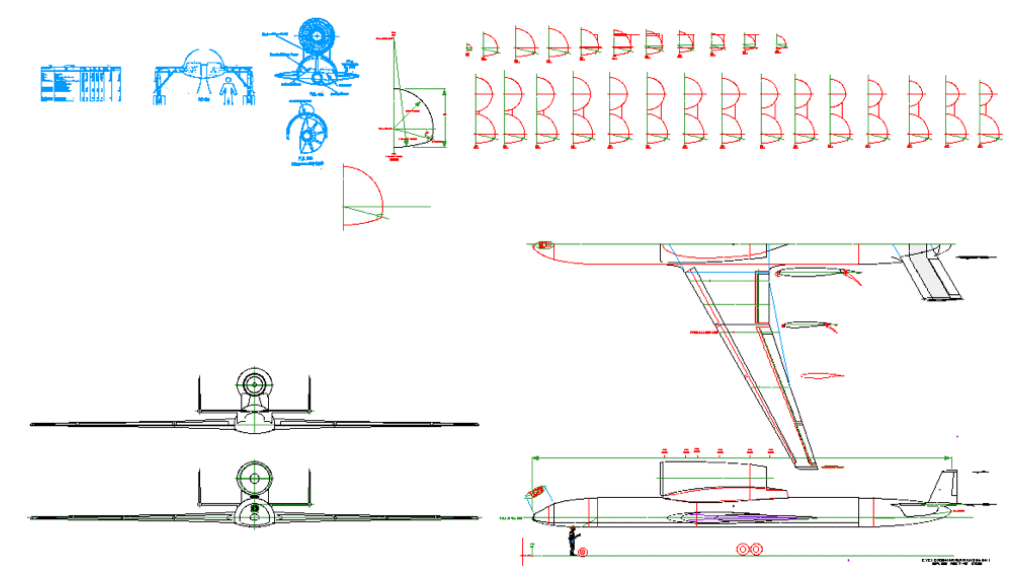

Figure 3. Cyclops, AIAA 1999-2000 Competition Winner.

\section{Vendetta in $\mathbf{2 0 0 2}$}

The 2001-2002 RFP called for a low observable supersonic cruise interdictor capable of carrying smart bombs, air-to-air, and air-to-ground missiles. As a result of these conflicting requirements, Vendetta went through a torturous design cycle during the academic year. As discussed in other parts of this paper, one major strength of the senior aircraft design sequence at Cal Poly is its close ties to industry that includes multiple briefings to industry as designs progress during the second two-thirds of the academic year. This particular year, visit schedules required back-to-back preliminary design reviews (PDRs) with one at the end of winter quarter and the second ten days later at the end of the first week of spring quarter. There had also been a configuration status review at the end of January, during which both competing teams that year received negative feedback on their approach to reduce observability, among other operational and design considerations. As a result of the January review, members of Team Vendetta found two white world radar cross-section (RCS) applications that would run on PCs and convinced one company to provide RADBase to the design lab for the duration of the competition. Renee Pasman, who worked in the lab on designrelated research projects but who had not taken senior design yet, was the RADBase Guru and provided consistently excellent RCS analyses of student designs as they evolved. By the March PDRs, the code was running well enough, and students were familiar enough with it, that Team Vendetta completely redesigned their aircraft between PDRs, including supersonic area ruling as well as iterations to reduce RCS. Cal Poly submitted two proposals that year; the other, Assailant, took third place. Ms. Pasman and Dan Salluce of Team Vendetta also provided the Air Force Academy with RCS analyses and redesign guidelines for their three entries in the same competition.

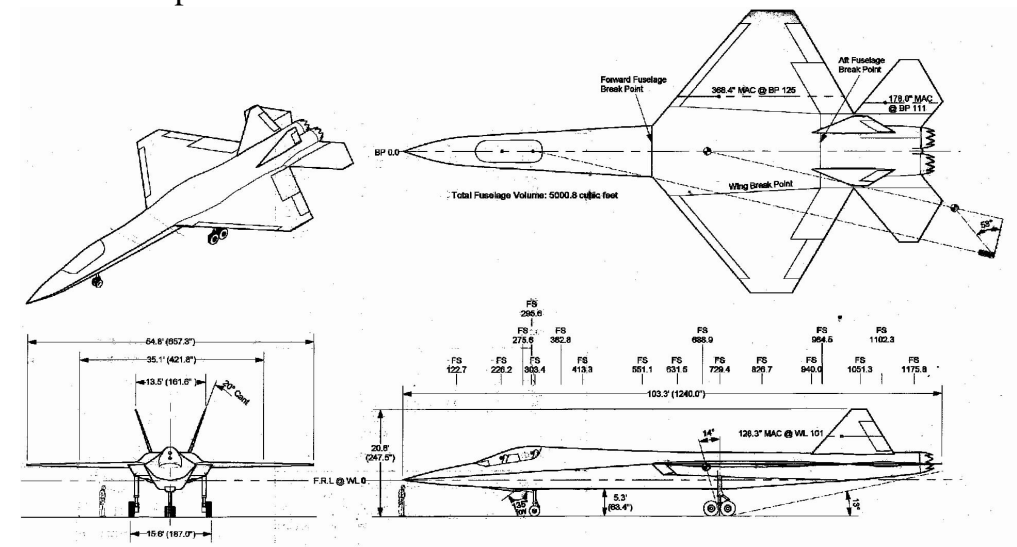

Figure 4. Vendetta, AIAA 2001-2002 Competition Winner.

American Institute of Aeronautics and Astronautics 092407 


\section{Hyperion in $\mathbf{2 0 0 3}$}

The 2002-2003 AIAA undergraduate team aircraft design competition focused on a heavy lifter capable of carrying ten Abrams tanks with transatlantic range and 500 knot cruise speed and being capable of taking off and landing on standard 8000 foot NATO runways. The designs worked out to about a 1.4 million pound payload and a roughly 3 million pound TOGW which immersed design students in the problems of operating very heavy aircraft from existing airports. As a result, students became very familiar with tire flotation and footprint as well as operational wingspan limitations. For a while, Team Hyperion looked at a ten engine solution with six engines providing cruise thrust and four dedicated to keeping a humongous airbag inflated in place of conventional landing gear. The air cushion landing system went away as practical design, maintenance, and operational considerations came into play. At one point, it became obvious to the design team that the CONOPS for this ultra heavy lift transport was to maximize "pounds on the ground" and that drove Team Hyperion to extensive throughput analyses using multiple aircraft feeding into one standard NATO landing area. These analyses showed that reducing cruise speed to 450 knots actually increased pounds on the ground over a 24 hour period, made the aircraft physically smaller, and reduced the number of cruise engines from to six. Hence, the final Hyperion design incorporated a swept and staggered biplane layout with engines mounted to provide externally blown flap effects for the upper wing and over-wing blowing effects for the lower one on takeoffs and landings. Research projects going on in the design lab during this period focused on STOL performance, and it was not lost on Team Hyperion that an 8000 foot field requirement demanded STOL performance from a three million pound airplane. Hyperion is an example of letting operationally focused analyses drive the design rather than published requirements.

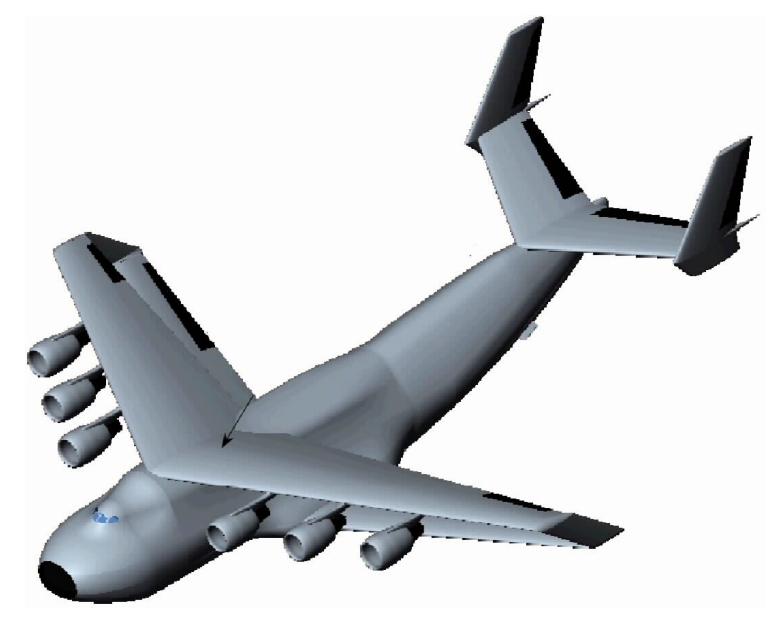

Figure 5. Hyperion, AIAA 2002-2003 Competition Winner.

\section{Conclusions}

Design continues to be the poor stepchild of academia but, as shown here, can be the crucible for creating talented and capable young engineers for productive careers in industry and Government if taken seriously. This is all predicated, of course, on aerospace engineering students receiving a high quality education in the traditional specialty areas and the production of high quality graduates requires a dedicated team approach by all aero faculty members. This has been a historic strength of the Cal Poly learn-bydoing approach. 


\section{Appendix}

There have been numerous external validations of the success of the aircraft design curriculum at $\mathrm{Cal}$ Poly. These include a high rate of placement of graduates in design positions in industry and increased industry involvement and support of the design curriculum. But the most gratifying validation has been the unprecedented achievement of our students in the AIAA Team and Individual Design Competitions. The following table shows how this success has grown over time, and even transcended the confines of the aircraft design course.

\begin{tabular}{|c|c|c|c|c|c|}
\hline Year & UG Team A/C & UG Ind. A/C & UG Team Engine & Grad Team A/C & DBF \\
\hline $90-91$ & 3 & & & & \\
\hline 93-94 & 2 & & & & \\
\hline $94-95$ & 2,3 & 1 & & & \\
\hline $95-96$ & $1,2, \mathrm{HM}$ & & & & \\
\hline 96-97 & 1,2 & & & & \\
\hline $97-98$ & 2 & & & & \\
\hline $98-99$ & 1 & & & & \\
\hline $99-00$ & 1 & & & & \\
\hline $00-01$ & 2 & & 1 & & 2 \\
\hline $01-02$ & 1,3 & & 3 & & \\
\hline $02-03$ & 1 & 1,2 & 3 & & 2 \\
\hline $03-04$ & 1 & & & 1 & \\
\hline 04-05 & $1,2,3$ & 1 & 1 & 2 & \\
\hline $05-06$ & 1,2 & & 2 & & 3 \\
\hline 06-07 & $1,2,3$ & & 1 & & \\
\hline
\end{tabular}

$1=1^{\text {st }}$ Place award

$2=2^{\text {nd }}$ Place award

$3=3^{\text {rd }}$ Place award

$\mathrm{HM}=$ Honorable Mention
$\mathrm{UG}=$ UnderGraduate

$\mathrm{G}=$ Graduate

$\mathrm{A} / \mathrm{C}=$ Aircraft

$\mathrm{DBF}=$ Design/Build/Fly 


\section{Acknowledgments}

The authors wish to thank the hundreds of students who have taken our aircraft design courses for their feedback, suggestions, and unknowing contributions to the improvements in our teaching methods. Without their participation we would not have known how to improve our course. We are especially grateful to Robert van't Riet for sharing various ideas and experiences from his time as the aircraft design instructor, and to Mark Waters for his support of the design course over the past ten years. In addition, the aircraft design course has been given a great deal of financial and moral support from various engineers in the aerospace industry and at government laboratories, which has helped to make the course much more real to our students. We want to thank John McMasters of The Boeing Company for his support of our ideas and for many fruitful (and enjoyable) discussions about aircraft design education. Finally, we also want to thank Dr. John Zuk, Doug Wardwell, and Craig Hange at NASA Ames Research Center, and Joe Lusczek at Air Force Air Systems Command for their generous support of the design course.

\section{References}

${ }^{1}$ Sandlin, D.R. and van't Riet, R., “The Cal Poly Aircraft Design Program,” AIAA Aerospace Design Conference, Irvine CA, AIAA Paper 93-1111, Feb. 1993.

${ }^{2}$ Soban, D.S., “Aircraft Design Education-A Student's Perspective," AIAA Aircraft Design, Systems, and Operations Meeting, Monterey CA, AIAA Paper 93-3993, Aug. 1993.

${ }^{3}$ Cummings, R.M., "From Biplanes to Reusable Launch Vehicles: 75 Years of Aircraft Design at Cal Poly," AIAA 41 ${ }^{\text {st }}$ Aerospace Sciences Meeting, Reno NV, AIAA Paper 2003-0233, Jan. 2003.

${ }^{4}$ Marchman, J.F. and Mason, W.H., "Freshman/Senior Design Education," AIAA $32^{\text {nd }}$ Aerospace Sciences Meeting, Reno NV, AIAA Paper 94-0857, Jan. 1994.

${ }^{5}$ Hollister, W.M., Crawley, E.F., and Amir, A.R., "Unified Engineering: A Twenty Year Experiment in Sophomore Aerospace Education at MIT," AIAA 32 ${ }^{\text {nd }}$ Aerospace Sciences Meeting, Reno NV, AIAA Paper 94-0851, Jan. 1994.

${ }^{6}$ Jenkinson, L.R., Page, G.J., and Marchman, J.F., "Model for International Teaming in Aircraft Design Education," Aircraft Design, Vol. 3, No. 4, 2000, pp. 239-247.

${ }^{7}$ Cummings, R.M. and Freeman, H.J., "Integrating Multidisciplinary Design in an Undergraduate Curriculum," $S A E$ Transactions, Vol. 106, No.1, 1997, pp. 1665-1670.

${ }^{8}$ Cummings, R.M. and Hall, D., "Aircraft Design for Second-Year Undergraduate Students," International Journal of Engineering Education, Vol. 21, No. 2, 2005, pp. 341-349.

${ }^{9}$ McMasters, J.M. and Cummings, R.M., “Aircraft Design-Past, Present, and Future,” Journal of Aircraft, Vol. 39, No. 1, 2002, pp. 10-17.

${ }^{10}$ Cummings, R.M. and McMasters, J.M., "Technology and You: Working with the Aerospace Industry to Enhance Engineering Education,” ASEE Annual Meeting, Portland OR, ASEE Paper 2005-0925, June 2005.

${ }^{11}$ Cummings, D.B. and Hall, D.W., "Exploiting the Creative Process for Innovative Air Vehicle Design," AIAA 42 ${ }^{\text {nd }}$ Aerospace Sciences Meeting, Reno NV, AIAA Paper 2004-0417, Jan. 2004.

${ }^{12}$ Hall, D.W., and Cummings, R.M., "The Happy Accidents of Teaching Aircraft Design," AIAA 45 ${ }^{\text {th }}$ Aerospace Sciences Meeting, Reno NV, AIAA Paper 2007-0302, Jan. 2007.

${ }^{13}$ Johnson, V.S., "Tying it all Together-The NASA/USRA University Advanced Design Program," AIAA Aerospace Design Conference, Irvine CA, AIAA Paper 92-1040, Feb. 1992.

${ }_{14}$ Johnson, V.S., and Rumbaugh, B.A., "Educating for Engineering Design Today-Measuring for Excellence Tomorrow: The NASA/USRA University Advanced Design Program," AIAA $32^{\text {nd }}$ Aerospace Sciences Meeting, Reno NV, AIAA Paper 940862, Jan. 1994.

${ }^{15}$ Furgason, R.R., "Update on ABET Accreditation Activities," ABET Memo to Engineering Deans, April 1994.

${ }^{16}$ Nicolai, L.M., “An Industry View of Engineering Design Education,” AIAA Paper 93-0328, Jan. 1993.

${ }^{17}$ Roskam, J., "What is Needed to Teach Aeronautical Engineering Students How to Design Aircraft?," Aircraft Design, Systems and Operations Conference, Dayton OH, AIAA Paper 90-3257, Sept. 1990.

${ }^{18}$ Nowaczyk, R., and Levi, D., "Two Approaches to Teaching Team Skills to Engineering and Science Students," $6{ }^{\text {th }}$ Symposium on Multidisciplinary Analysis and Optimization, Bellevue WA, AIAA Paper 96-4068, Sept. 1996. 